\title{
Effect of cell cycle phase on the sensitivity of SAS cells to sonodynamic therapy using low-intensity ultrasound combined with 5-aminolevulinic acid in vitro
}

\author{
NAN LI ${ }^{1,2^{*}}$, MIAO SUN $^{3 *}$, YAO WANG $^{4}$, YANHONG LV $^{4}$, ZHENG HU $^{2}$, \\ WENWU CAO ${ }^{2,5}$, JINHUA ZHENG ${ }^{2,4,5}$ and XIAOHUI JIAO ${ }^{1}$
}

\begin{abstract}
${ }^{1}$ Department of Oral Maxillofacial Surgery, School of Stomatology, Harbin Medical University, Harbin, Heilongjiang 150001;
${ }^{2}$ Laboratory of Sono- and Photo-theranostic Technologies, Harbin Institute of Technology, Harbin, Heilongjiang 150080;

${ }^{3}$ Department of Stomatology, The Fourth Clinical College, Harbin Medical University, Harbin, Heilongjiang 150001;

${ }^{4}$ Department of Anatomy, Basic Medical Science College, Harbin Medical University, Harbin, Heilongjiang 150081,

P.R. China; ${ }^{5}$ Materials Research Institute, Pennsylvania State University, University Park, PA 16802, USA
\end{abstract}

Received July 20, 2014; Accepted March 26, 2015

DOI: $10.3892 / \mathrm{mmr} .2015 .3747$

\begin{abstract}
Sonodynamic therapy (SDT) with 5-aminolevulinic acid (5-ALA) can effectively inhibit various types of tumor in vitro and in vivo. However, the association between the efficacy of SDT and the phase of the cell cycle remains to be elucidated. 5-ALA may generate different quantities of sonosensitizer, protoporphyrin IX (PpIX), in different phases of the cell cycle, which may result in differences in sensitivity to 5-ALA-induced SDT. The present study aimed to investigate the effect of the cell cycle on the susceptibility of SAS cells to SDT following synchronization to different cell cycle phases. These results indicates that the rates of cell death and apoptosis of the SAS cells in the $S$ and $\mathrm{G}_{2} / \mathrm{M}$ phases were significantly higher following SDT, compared with those in the G1-phase cells and unsynchronized cells, with a corresponding increase in PpIX in the $S$ and $G_{2} / M$ cells. In addition, the expression of caspase-3 increased, while that of B-cell lymphoma (Bcl)-2 decreased markedly in theS and $\mathrm{G}_{2} / \mathrm{M}$ cells following SDT. Cyclin A was also expressed at higher levels in the $S$ and $G_{2} / M$ cells, compared with the G1-phase cells. SDT also caused a significant upregulation of cyclin A in all phases of the cell
\end{abstract}

Correspondence to: Professor Xiaohui Jiao, Department of Oral Maxillofacial Surgery, School of Stomatology, Harbin Medical University, 143 YiMan Road, Harbin, Heilongjiang 150001, P.R. China E-mail: jxhln@hotmail.com

Professor Jinhua Zheng, Department of Anatomy, Basic Medical Science College, Harbin Medical University, 157 Baojian Road, Harbin, Heilongjiang 150081, P.R. China

E-mail: jhzheng@ems.hrbmu.edu.cn

*Contributed equally

Key words: sonodynamic therapy, apoptosis, SAS cells, cell cycle, cyclin A cycle, however this was most marked in the $\mathrm{S}$ and $\mathrm{G}_{2} / \mathrm{M}$ cells. It was hypothesized that high expression levels of cyclin $\mathrm{A}$ in the $\mathrm{S}$ and $\mathrm{G}_{2} / \mathrm{M}$ cells may promote the induction of caspase- 3 and reduce the induction of Bcl-2 by SDT and, therefore, enhance apoptosis. Taken together, these data demonstrated that cells in The $S$ and $G_{2} / M$ phases generate more intracellular PpIX, have higher levels of cyclin $\mathrm{A}$ and are, therefore, more sensitive to SDT-induced cytotoxicity. These findings indicate the potential novel approach to preventing the onset of cancer by combining cell-cycle regulators with SDT. This sequential combination therapy may be a simple and cost-effective way of enhancing the effects of SDT in clinical settings.

\section{Introduction}

Sonodynamic therapy (SDT), using low-intensity ultrasound combined with a sonosensitizer, is a promising approach to cancer therapy, which has rapid progressed in previous years $(1,2)$. In vitro and in vivo experiments have demonstrated that SDT can effectively inhibit several types of cancer cells (3-7). 5-Aminolevulinic acid (5-ALA) itself is not a sonosensitizer, however, it is the prodrug of protoporphyrin IX (PpIX). PpIX is a sonosensitizer, which preferentially accumulates in tumor cells, but not in normal tissues (8) due to an imbalance of porphobilinogen deaminase activity and thus ferrochelatase activity in neoplastic tissues $(9,10)$. Schick et al (11) and Wyld et al (12) reported that, compared with resting cells, proliferating cells generate more PpIX following incubation with 5-ALA. Thus, 5-ALA may produce different quantities of PpIX in different cell cycle phases, leading to differential sensitivity to 5-ALA-SDT. Therefore, the presents study hypothesized that susceptibility to SDT is likely to be associated with certain phases of the cell cycle of tumor cells.

Previous studies have suggested that the antitumor effects of several cancer therapeutic approaches are associated with the phase of the cell cycle (13-16). Certain appropriate chemotherapeutic agents, which induce cell cycle arrest at 
the $S$ phase or $\mathrm{G}_{2} / \mathrm{M}$ phase increase the overall viral replication and then potentiate viral oncolysis $(15,17,18)$. In human myeloma cell lines, the cytotoxicity induced by bortezomib, is markedly amplified in synchronous $\mathrm{S}$ phase entry and progression (16). Thus, the phase of the cell cycle can affect tumor sensitivity to anticancer treatments.

At present, the mechanisms underlying SDT-induced cancer cell death remain to be fully elucidated. Few studies have investigated the association between cell cycle phase and the effect of SDT on tumor cells. Our previous investigations demonstrated the effects of 5-ALA-induced SDT on human tongue squamous carcinoma $(19,20)$. The present study aimed to investigate the production of PpIX in different phases of the cell cycle and the effects of these phases on the susceptibility of the cells to SDT-induced cell death. The differential expression of apoptosis-associated factors and enrichment of cyclins in certain cell cycle phases were also examined. Determination of the likely underlying mechanism may provide a theoretical basis for optimizing the application of SDT in oncology.

\section{Materials and methods}

Cell culture. The human tongue cancer SAS cell line was obtained from the Human Science Research Resources Bank (Osaka, Japan). The SAS cells were cultured in Roswell Park Memorial Institute (RPMI)-1640 medium (GE Healthcare, Logan, UT, USA) at $37^{\circ} \mathrm{C}$ and $5 \% \mathrm{CO}_{2}$. The RPMI1640 medium was supplemented with $10 \%$ heat-inactivated fetal bovine serum (FBS; GE Healthcare), $100 \mathrm{U} / \mathrm{ml}$ penicillin and $100 \mu \mathrm{g} / \mathrm{ml}$ streptomycin (GE Healthcare).

Cell cycle synchronization. To synchronize the cells to the $\mathrm{G}_{0} / \mathrm{G}_{1}$ phase, the SAS cells were arrested by serum starvation (21). The exponentially growing cells $\left(1 \times 10^{6}\right.$ cells) were plated onto dishes containing RPMI-1640 without FBS, and incubated at $37^{\circ} \mathrm{C}$ for $48 \mathrm{~h}$ prior to harvesting. The SAS cells were synchronized to the $\mathrm{S}$ phase using Banfalvi's double thymidine block method (22). The exponentially growing cells were incubated at $37^{\circ} \mathrm{C}$ with $2 \mathrm{mM}$ thymidine (Sigma-Aldrich, St. Louis, MO, USA) for $21 \mathrm{~h}$, washed with PBS (Hyclone, Logan City, UT, USA) and placed in fresh RPMI-1640 medium with 10\% FBS for $18 \mathrm{~h}$. Subsequently, the cells were retreated with $2 \mathrm{mM}$ thymidine for $21 \mathrm{~h}$. Following release from the second inhibition at $37^{\circ} \mathrm{C}$ for $2 \mathrm{~h}$, the cells were synchronized to the $\mathrm{S}$ phase. To arrest the cells at the $\mathrm{G}_{2} / \mathrm{M}$ junction, the $S A S$ cells were incubated at $37^{\circ} \mathrm{C}$ with $100 \mathrm{ng} / \mathrm{ml}$ nocodazole (Sigma-Aldrich) for $20 \mathrm{~h}$, washed twice with PBS, resuspended in fresh RPMI-1640 medium with $10 \% \mathrm{FBS}$ for $1 \mathrm{~h}$ and harvested. Following synchronization to the $\mathrm{G}_{1}, \mathrm{~S}$ and $\mathrm{G}_{2} / \mathrm{M}$ phases, the cells from each phase were allowed to grow in RPMI-1640 medium with $10 \%$ FBS. The present study used cells that were normal cycling $(\mathrm{N})$, G1-phase (G1), S-phase (S) and G2/M-phase (G2/M) cells. The cells were sampled after $0,1,2,3$ and $4 \mathrm{~h}$, following which flow cytometry analysis was performed to assess cell cycle duration.

Flow cytometric analysis of DNA content. Following cell cycle synchronization, the cells $\left(1 \times 10^{6}\right)$ were harvested by trypsinization ( $0.25 \%$ trypsin; Hyclone) and washed twice in cold phosphate-buffered saline (PBS). The cells were fixed in 70\% ethanol (Luck Mouse, Changzhou, China) and stored at $4{ }^{\circ} \mathrm{C}$ overnight. The fixed cells were resuspended in PBS containing $2.5 \mathrm{mg} / \mathrm{ml}$ RNase A (Sigma-Aldrich) and $1 \mathrm{mg} / \mathrm{ml}$ propidium iodide (Sigma-Aldrich), and incubated for $30 \mathrm{~min}$ at $37^{\circ} \mathrm{C}$. Following filtration through a nylon mesh (300 mesh; Yuexing, Guangzhou, China), the cells were evaluated using flow cytometry (FACSCalibur; BD Biosciences, Franklin Lakes, NJ, USA), and the results were analyzed using ModFit LT version 4.0 software (Verity Software House, Topsham, ME, USA).

PpIX determination. The SpectraMax 5 microplate reader (Molecular Devices, Sunnyvale, CA, USA) was selected to detect the production of 5-ALA-induced PpIX in the SAS cells (excitation, $405 \mathrm{~nm}$; emission, $590 \mathrm{~nm}$ ). The correlation between the fluorescence intensity of the samples and the exogenous PpIX concentrations were assessed, following which a standard curve of PpIX was constructed using SPSS 13.0 softward (SPSS, Inc., Chicago, IL, USA). The SAS cells were seeded into a 96 -well plate $\left(2 \times 10^{4}\right.$ cells/well $)$ and cultivated for $24 \mathrm{~h}$ in RPMI-1640 medium. At the time-points corresponding to each phase of the cell cycle following synchronization, as described above, the cells were incubated with $1 \mathrm{mM}$ 5-ALA in RPMI-1640 medium for $2 \mathrm{~h}$ in the dark at $37^{\circ} \mathrm{C}$. The cells were then washed three times with PBS and the concentrations of PpIX in the cells in each cell cycle phase were determined using the microplate reader. The fluorescence intensity indicated the level of intracellular PpIX.

Ultrasonic device. Following synchronization, the cells treated with SDT (Harbin Institute of Technology, Harbin, China) were incubated with $1 \mathrm{mM}$ 5-ALA in the dark for $2 \mathrm{~h}$ at $37^{\circ} \mathrm{C}$. The ultrasound treatment system used in the present study, as shown in Fig.1, was designed and manufactured by the Harbin Institute of Technology (Harbin, China). This ultrasonic device has been described in a previous publication (23). A $3.5 \mathrm{~cm}$ petri dish containing the cultured cells was placed in center of the transducer. The cells were exposed to ultrasound $\left(1.0 \mathrm{MHz} ; 0.05 \mathrm{~W} / \mathrm{cm}^{2} ; 10 \%\right.$ duty cycle) for varying durations (1,2 and $3 \mathrm{~min})$, in the dark. Following treatment, the cells were either harvested or incubated continuously for subsequent analyses.

Cell survival assays. Following treatment with SDT, the cells were harvested and reseeded into 96-well plates at a density of $1 \times 10^{4}$ cells/well for $24 \mathrm{~h}$. The cell viability was subsequently determined using a Cell Counting kit (CCK)-8 (Beyotime Institute of Biotechnology, Nantong, China), according to the manufacturer's instructions. The absorbance value (AV) was measured at $450 \mathrm{~nm}$ using a SpectraMax 5 microplate reader. The absorbance data were expressed as the percentage survival, which were corrected for background and compared with the controls using the following formula: AV of test well / AV of control well x $100 \%$.

Analysis of cell apoptosis. The cells of all the groups were harvested by trypsinization without EDTA and were washed three times with pre-cooled PBS. Apoptosis was detected using an Annexin V-Propidium Iodide (PI) Apoptosis Detection kit (Biosea Biotechnology, Beijing, China), according to the 


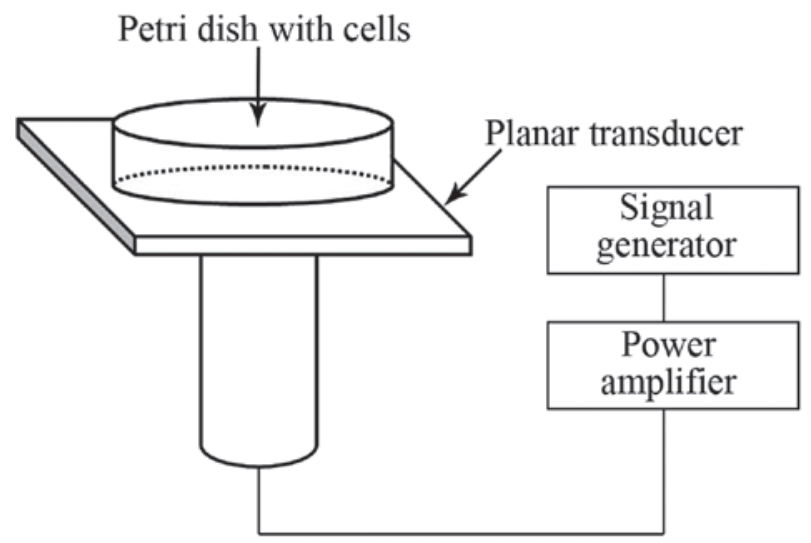

Figure 1. Schematic diagram of the ultrasonic device used for synchronization of the SAS cells.

manufacturer's instructions. The cells were re-suspended in $200 \mu \mathrm{l}$ binding buffer (Biosea Biotechnology, Beijing, China) and stained with annexin V $(10 \mu \mathrm{l})$ and PI $(5 \mu \mathrm{l})$ sequentially. Following incubation at $4^{\circ} \mathrm{C}$ for $30 \mathrm{~min}$ in the dark, the cells were counted using flow cytometry on a FACSCalibur flow cytometer.

Immunoblotting. The cells were lysed in radioimmunoprecipitation buffer for protein extraction. Equal concentrations $(50 \mu \mathrm{g})$ of protein from each sample were resolved on $10 \%$ polyacrylamide-sodium dodecyl sulfate gels (Beyotime Institute of Biotechnology Co., Ltd., Nantong, China) and electrophoretically transferred to polyvinylidene difluoride membranes (Beyotime Institute of Biotechnology Co., Ltd.). The membranes were blocked using non-fat dried milk (Wandashan, Harbin, China) for $1 \mathrm{~h}$; incubated overnight at $4^{\circ} \mathrm{C}$ with antibodies against human cyclin A (cat.no. sc-751), B-cell lymphoma (Bcl)-2 (cat.no. sc-492), caspase-3 (cat.no. sc-7148) and $\beta$-actin (cat.no. sc-130619; all rabbit polyclonal antibodies used at 1:200 from Santa Cruz Biotechnology Inc., Santa Cruz, CA, USA); and subsequently incubated for $2 \mathrm{~h}$ at $4^{\circ} \mathrm{C}$ with an horseradish peroxidase-conjugated goat anti-rabbit immunoglobulin $\mathrm{G}$ secondary antibody (1:5,000; cat. no. ZDR-5306; ZSGB-BIO, Beijing, China). The immunoreactive proteins were visualized, and the protein levels were normalized with respect to the band density of $\beta$-actin as an internal control. The protein bands were detected using an image analyzer (Quantity One; Bio-Rad Laboratories, Inc., Hercules, CA, USA) and an enzymatic chemilluminescence kit (Beyotime Institute of Biotechnology, Nantong, China).

Statistical analysis. All data are presented as the mean \pm standard deviation. The differences between groups were analyzed using Student's t-test. Statistical differences were evaluated using SPSS 13.0 software (SPSS, Inc., Chicago, IL, USA). $\mathrm{P}<0.05$ was considered to indicate a statistically significant difference.

\section{Results}

Synchronization effect and DNA content in different phases of the cell cycle. Figure 2A shows a histogram of the cell cycle based on flow cytometric analysis of the SAS cells following treatment with various synchronization methods. A single-parameter histogram of DNA enables discrimination of cell populations existing in the $\mathrm{G}_{0} / \mathrm{G}_{1}$ (2C DNA), $S$ (between $2 \mathrm{C}$ and $4 \mathrm{C}$ ) and $\mathrm{G}_{2} / \mathrm{M}(4 \mathrm{C}$ ) phases of the cell cycle. Based on these data, the synchronization performed in the present study was successful. The percentages of cells in the $G_{0} / G_{1}, S$ and $G_{2} / M$ phases in the normal SAS cells increased between $60.58 \pm 2.8,28.74 \pm 1.1$, and $10.68 \pm 0.9 \%$ and $92.48 \pm 9.4,70.59 \pm 2.7$ and $56.33 \pm 1.9 \%$, respectively $(\mathrm{P}<0.05)$. The durations of different phases of the cell cycle were calculated $0,1,2,3$ and $4 \mathrm{~h}$ following release from the different synchronization blocks (Fig. 2B). The percentage of cells in the G1- and S-phases remained high between 0 and $4 \mathrm{~h}$. The percentage of cells in the $\mathrm{G}_{2} / \mathrm{M}$ phase decreased $4 \mathrm{~h}$ after release. These results indicated that, following incubation with 5-ALA for $2 \mathrm{~h}$ following phase synchronization, the cells remained within the limit of that particular phase and did not transit to the next phase of the cell cycle.

Production of PpIX in different cell cycle phases. A standard curve was plotted, according to the fluorescence intensity of a known gradient concentration of exogenous PpIX (Fig. 3A). A positive linear correlation was observed between the fluorescence intensity and the concentrations of PpIX in the liquid phantom (correlation index $\mathrm{R}^{2}=0.9983$ ). Therefore, the fluorescence intensity was indicative of the level of 5-ALA-induced PpIX in each phase of the cell cycle. Subsequently, the present study investigated the production of PpIX from synchronized cells treated with 5-ALA for $2 \mathrm{~h}$. As shown in Fig. 3B, 5-ALA administration yielded significantly higher PpIX fluorescence intensities in the $S$ and $G_{2} / M$ phases, compared with the normal cycling cells and $\mathrm{G}_{1}$ cells $(\mathrm{P}<0.05)$. These results suggested that the production of $\mathrm{PpIX}$ from exogenous 5-ALA was higher in the $S-$ and $\mathrm{G}_{2} / \mathrm{M}$ phase compared with the $\mathrm{G}_{1}$ phase cells. Thus, it was hypothesized that the increase in cell death was, at least in part, due to an increase in the production of PpIX compared with that of normal cycling cells and $\mathrm{G}_{1}$-phase cells.

Cell survival and apoptosis in different phases of the cell cycle following SDT. The CCK8 assay revealed that, following SDT, the cell viability was higher in the asynchronous cells and G1 cells compared with that in the $\mathrm{S}$-phase and $\mathrm{G}_{2} / \mathrm{M}$-phase cells ( $P<0.05$; Fig. 4A). The sensitivity of $\mathrm{S}$ and $\mathrm{G}_{2} / \mathrm{M}$ cells to SDT increased markedly as the duration of sonication increased between 1 and $3 \mathrm{~min}$. The apoptotic rates of the cells were almost identical in the normal cycling cells and $G_{1}$ cells following SDT treatment (Fig. 4B). However, the cells in the $\mathrm{S}$ and $\mathrm{G}_{2} / \mathrm{M}$ phases exhibited a significantly higher apoptotic rate, compared with the other groups $(\mathrm{P}<0.05)$. Specifically, there was a $20.91 \%$ increase in apoptotic rate in the S-phase cells, compared with the unsynchronized cells.

Effect of cell cycle on apoptotic cytokines and cyclin A in SDT treatment. The results of the western blot analysis (Fig. 5), demonstrated that caspase-3 was significantly increased in the cells in the $S$ and $G_{2} / M$ phases following SDT treatment $(\mathrm{P}<0.05)$, with the opposite change in Bcl-2 $(\mathrm{P}<0.05)$. The expression of cyclin A also peaked in the cells in the $\mathrm{S}$ and 
A
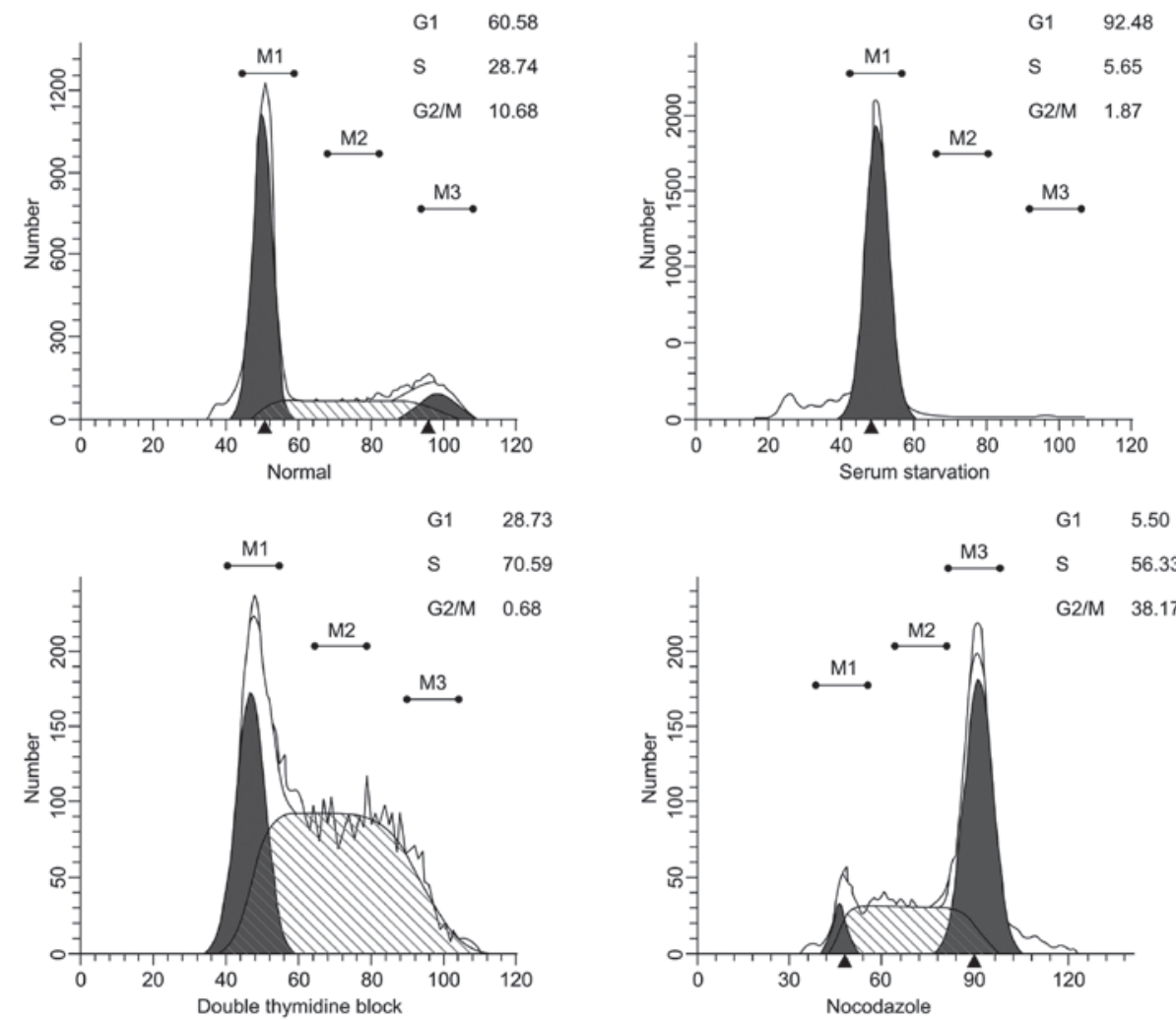

$\mathbf{B}$

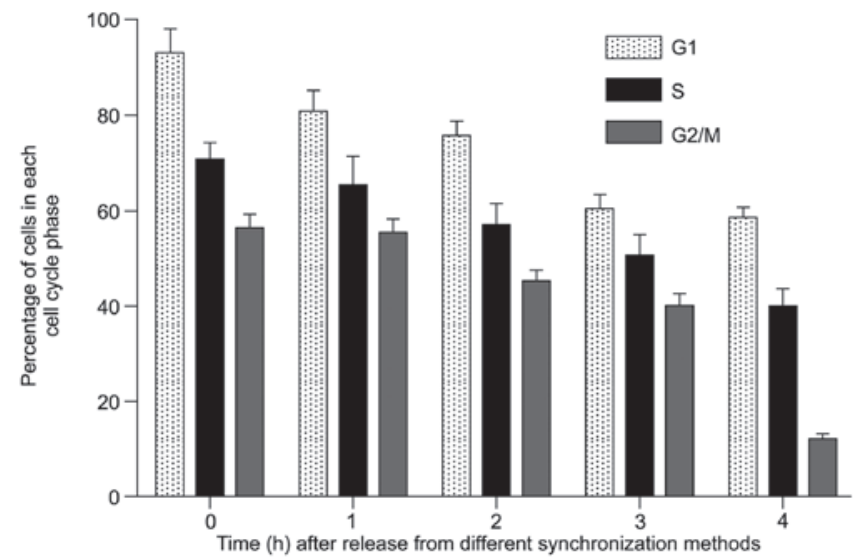

Figure 2. Cell distributions in different phases of the cell cycle were determined using fluorescence-activated cell sorting following synchronization and release for different durations. (A) Representative histograms of DNA content using flow cytometry of normal SAS cells and cells subjected to the different synchronization methods of serum starvation, double thymidine block and nocodazole incubation ( $n=6) . M_{1}, G_{0} / G_{1}(2 C$ DNA); M2, S (between $2 \mathrm{C}$ and $4 \mathrm{C}$ ); M3, $G_{2} / M(4 C)$. (B) Percentages of cells in the $G_{0} / G_{1}, S$ and $G_{2} / M$ phases of the cell cycle at different time-points following release from synchronization. The proportion of cells in the $\mathrm{G}_{0} / \mathrm{G}_{1}, \mathrm{~S}$, and $\mathrm{G}_{2} / \mathrm{M}$ remained high at $2 \mathrm{~h}(\mathrm{n}=6)$. Data are presented as the mean \pm standard deviation.

A

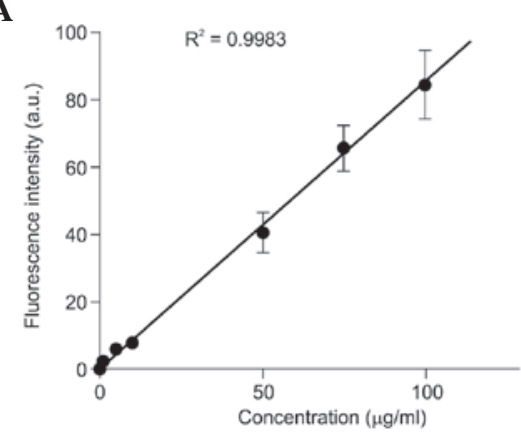

B

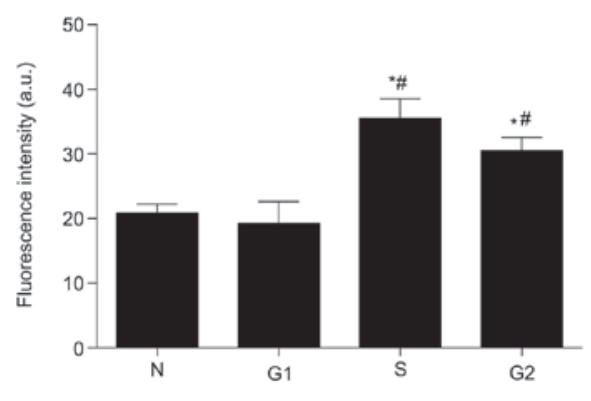

Figure 3. Levels of 5-ALA-derived PpIX differed among the cells in the different phases of the cell cycle. (A) Standard curve of the concentration of PpIX, vs. fluorescence intensity ( $n=3$ ). (B) Differences in PpIX fluorescence intensity between cells in different phases of the cell cycle following incubation with 5-ALA for $2 \mathrm{~h}(\mathrm{n}=6)$. Data are presented as the mean \pm standard deviation. ${ }^{*} \mathrm{P}<0.05$, vs. $\mathrm{N}$ grorup; ${ }^{\#} \mathrm{P}<0.05$, vs. $\mathrm{G}_{1}$-phase group. 5-ALA, 5-aminolevulinic acid; PpIX, protoporphyrin IX; N, normal cycling. 
A
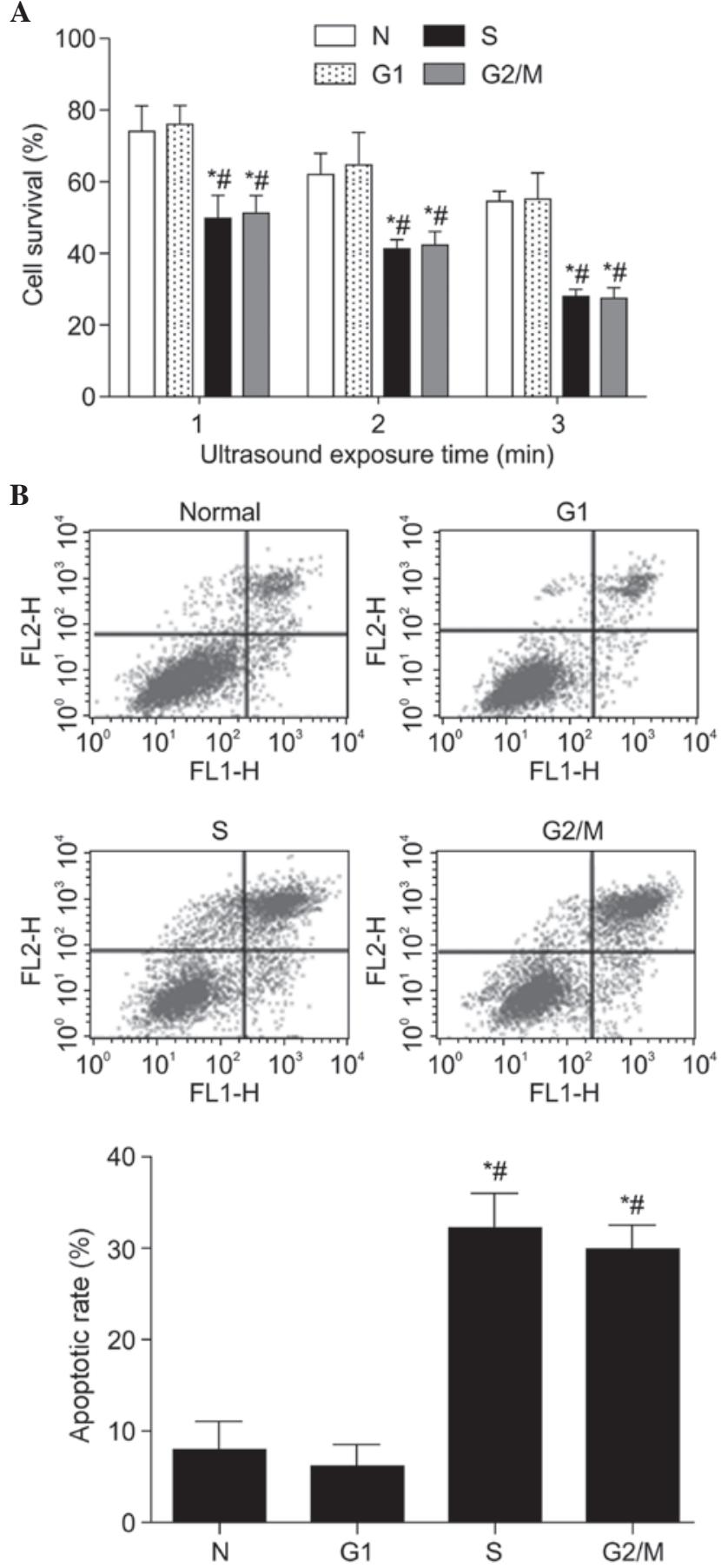

Figure 4. Cell cycle phase affects the sensitivity of SAS cells to SDT using 5 -aminolevulinic acid. Data are presented as the mean \pm standard deviation. (A) Survival rates of SAS cells in different cell cycle phases following SDT with ultrasound for 1, 2 and 3 min $(n=6)$. (B) Effect of different cell cycle phases on the SDT-induced apoptotic rates of the SAS cells, determined using fluorescence-activated cell sorting in vitro $(\mathrm{n}=6)$. Following synchronization to the $G_{1}, S$ and $G_{2} / M$ phases, the cells in each group were treated with SDT for $1 \mathrm{~min} .{ }^{*} \mathrm{P}<0.05$, vs. $\mathrm{N}$ group; ${ }^{\#} \mathrm{P}<0.05$, vs. $\mathrm{G}_{1}$-phase group. SDT, sonodynamic therapy; $\mathrm{N}$, normal cycling.

$\mathrm{G}_{2} / \mathrm{M}$ phases $(\mathrm{P}<0.05)$. SDT caused a significant upregulation of cyclin A in all groups, however this was most marked in the S-phase and $\mathrm{G}_{2} / \mathrm{M}$-phase cells. Cyclin A may have promoted SDT-induced caspase-3 and inhibited Bcl-2, which may be another contributor to the enhanced SDT-induced apoptosis in cells in the $\mathrm{S}$ and $\mathrm{G}_{2} / \mathrm{M}$ phases.
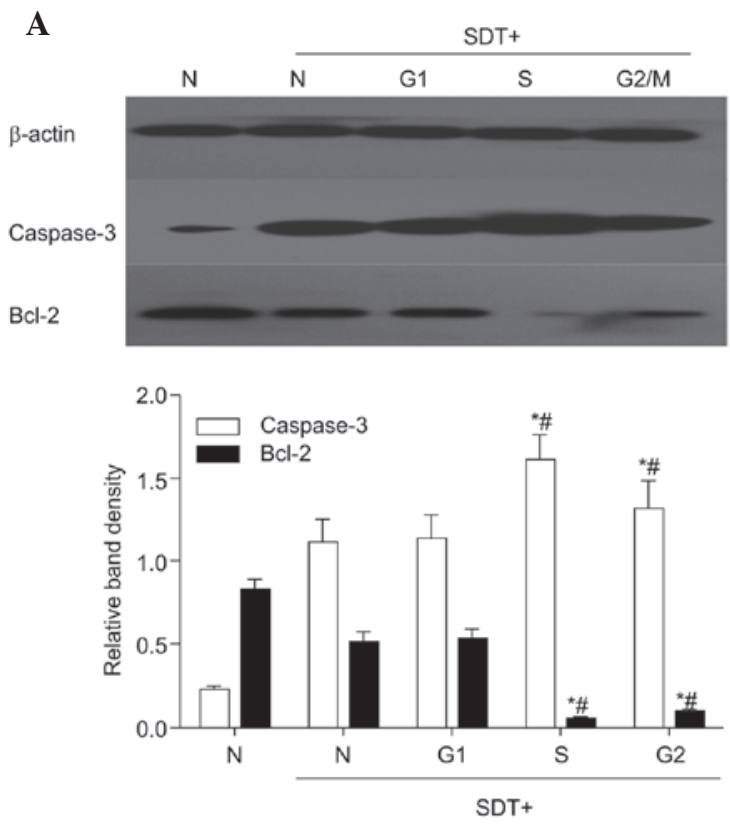

Cyclin A

$\mathbf{B}$
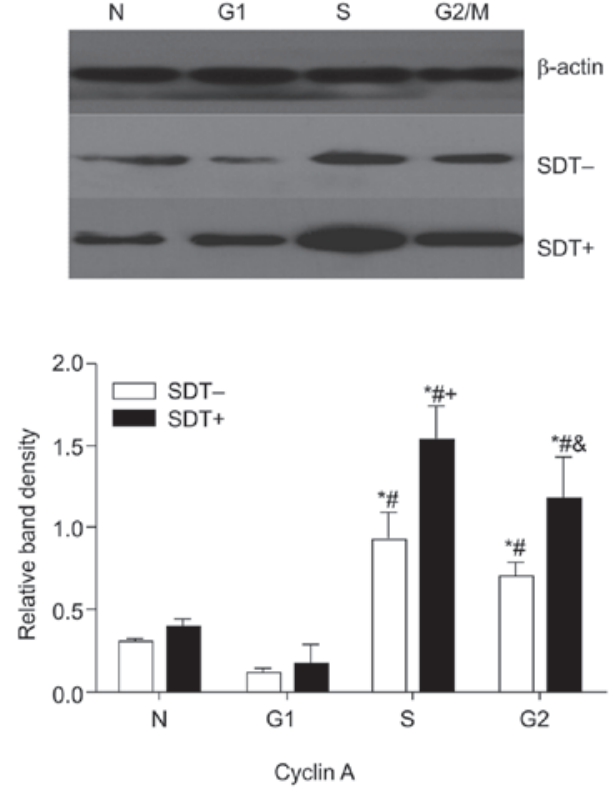

Figure 5. Effect of cell cycle on the expression levels of caspase-3 and Bcl-2 and cyclin A following SDT treatment. Data are presented as the mean \pm standard deviation. (A) Cells in each cell cycle group were lysed and subjected to western blot analyses to determine the expression of caspase- 3 and Bcl-2 ( $\mathrm{n}=6)$. ; ${ }^{*} \mathrm{P}<0.05$, vs. $\mathrm{N}+\mathrm{SDT}$ group; ${ }^{\prime} \mathrm{P}<0.05$, vs. G1-phase + SDT group. (B) Expression levels of cyclin A were examined using western blot analysis prior to and following SDT treatment in four groups $(\mathrm{n}=6)$.. ${ }^{*} \mathrm{P}<0.05$, vs. $\mathrm{N}$ group; ${ }^{\#} \mathrm{P}<0.05$, vs. $\mathrm{G}_{1}$-phase group; ${ }^{+} \mathrm{P}<0.05$, vs. $\mathrm{S}+\mathrm{SDT}-,{ }^{\circledR} \mathrm{P}<0.05$, vs. $\mathrm{G}_{2} / \mathrm{M}+\mathrm{SDT}-$. SDT, sonodynamic therapy; Bcl-2, B-cell lymphoma 2; SDT-, no SDT; SDT+, 1 min SDT; N, normal cycling.

\section{Discussion}

Cell cycle synchronization is a well-established technique to augment the efficacy of conventional cytotoxic anticancer therapy (24). The metabolic activity of a cell and the activity of cellular enzymes can vary with the phase of the cell cycle $(12,13)$. The effect of cancer treatment, including 
chemotherapy, radiotherapy, photodynamic therapy (PTD) and oncolytic virus therapy is associated with the cell cycle $(13,15,16,25,26)$.

In the present study, the levels of 5-ALA-induced PpIX were higher in the cells in the $\mathrm{S}$ and $\mathrm{G}_{2} / \mathrm{M}$ phases, compared with those in the G1 phase and in the unsynchronized cells (Fig. 2), similar to findings reported by Wyld et al (13). Physiological processes, including macromolecule synthesis, metabolism and DNA synthesis enzyme activation are more active in the $S$ and $G_{2} / M$ phases than in other phases, which may be a major determinant of increased PpIX production in these phases. The varying cell surface area in different phases of the cell cycle has been considered to contribute to the cell cycle-dependent uptake of a sonosensitizer (14), however, the increase in low-density lipoprotein receptors and tumor-specific glycoprotein may also contribute (27). Different levels of PpIX, produced from 5-ALA, may elicit differing sensitivities to SDT in certain phases of the cell cycle.

In the present study, SAS cells were partially synchronized in vitro using serum starvation, double thymidine block and nocodazole to arrest the cells at the $\mathrm{G}_{1}, \mathrm{~S}$ and $\mathrm{G}_{2} / \mathrm{M}$ phases, respectively. The subsequent analysis of the synchronized DNA content analyses indicated a high level of synchronization and no damage to the cells (Fig. 1). The rate of cell survival following SDT treatment, following release from synchronization, was measured. The CCK8 assays revealed that, compared with the G1 phase and normal cycling SAS cells, the cells in the $S$ and $G_{2} / M$ phases were significantly more sensitive to SDT following treatment with 5-ALA (Fig. 3). The susceptibility to SDT was also positively correlated with the level of PpIX in the cells in different phases. This variability in sensitivity to SDT with cell cycle is in agreement with previous observations on the susceptibility of cells to radiotherapy (28) and PDT with several photosensitizers, including 5-ALA (13), photofrin II (26) and ATX-S10 (Na) (14).

In the present study, cancer cells with a high percentage of cells in the S-phase or high proliferative activity were more sensitive to SDT-induced apoptosis (Fig. 3B). The results revealed that the levels of Bcl-2 and caspase-3 fluctuated in a cell cycle-dependent manner. SDT treatment induced cells in the $\mathrm{S}$ and $\mathrm{G}_{2} / \mathrm{M}$ phases to produce less Bcl-2 and more caspase-3 than the levels in relative resting cells (Fig. 4A). Caspase-3 is a critical effector in mediating several forms of apoptosis, and our previous study demonstrated that SDT activates caspase- 3 to induce SAS cell apoptosis through the mitochondrial signaling pathway (19). The level of SDT-induced caspase- 3 increased in the $\mathrm{S}$ and $\mathrm{G}_{2} / \mathrm{M}$ phases, which may be due to these phases having a lower threshold for caspase-3 activation (16).

Cell cycle protein regulation and the induction of cell death may be closely associated, and these two events may account for how the phase of the cell cycle affects tumor cell sensitivity to SDT (29). Cyclin A begins to accumulate during the $\mathrm{S}$ phase and maintains high levels until metaphase (30). With the exception of its functions in mitosis, cyclin A is involved in the initiation and progression of DNA synthesis during the $\mathrm{S}$ phase (31) and in the regulation of apoptosis (32). The induction of apoptosis is uniformly associated with the activation of cyclin A, but not with cyclins $\mathrm{E}$ or B $(33,34)$. In addition, knockdown of the expression of cyclin A in K562 cells suppresses doxorubicin-induced growth arrest and apoptosis (35). Therefore, the present study investigated the role of cyclin A in the alteration in the sensitivity of cells to SDT in different cell cycle phases. The results confirmed that the protein expression levels of cyclin A were higher in cells in the $\mathrm{S}$ and $\mathrm{G}_{2} / \mathrm{M}$ phases compared with those in the G1-phase cells following synchronization, and SDT caused a significant upregulation of cyclin $A$ in all groups, particularly the $S$ and $\mathrm{G}_{2} / \mathrm{M}$ cells (Fig. 4B). The increased expression of cyclin A has been previously observed to correlate well with the activation of caspase-3 and increase in apoptotic rate $(36,37)$, in which the overexpression of cyclin A circumvents the anti-apoptotic capacity of the Bcl-2 oncogene. Therefore, the increase in cyclin $A$ in cells in the $S$ and $G_{2} / M$ phases may also explain why cells in these phases exhibiter higher apoptotic rates and sensitivity to SDT compared with those in the $\mathrm{G}_{1}$ phase.

In conclusion, the present study demonstrated that synchronizing SAS cells to the $\mathrm{S}$ or $\mathrm{G}_{2} / \mathrm{M}$ phase can significantly enhance SDT-induced cell growth arrest and apoptosis. This may be due to an increase in the production of PpIX in the $S$ and $G_{2} / M$ phases. In addition, increasing cyclin $A$ in cells in the $S$ and $G_{2} / M$ phases may enhance the sensitivity of the cells to SDT by inhibiting Bcl-2 and promoting caspase-3. The results of the present study suggest the possibility of combination therapy with SDT and chemotherapy. To enhance the effect of SDT on cancer therapy and reduce tumor recurrence, a tumor-cell synchronizing agent may be administered to induce the cells into a more sensitive cell cycle phase prior to SDT treatment.

\section{Acknowledgements}

The authors would like to thank Mr. Ming Fang (Department of Anatomy, Basic Medical Science College, Harbin Medical University, China), Mr. Chuanchuan Nan (Department of ICU, The First Affiliated Hospital of Harbin Medical University, China), Miss. Shan Wang and Miss. Xiuzi Gaozhong (Department of Anatomy, Basic Medical Science College, Harbin Medical University, China) for providing technical assistance.

\section{References}

1. Shibaguchi H, Tsuru H and Kuroki M: Sonodynamic cancer therapy: a non-invasive and repeatable approach using low-intensity ultrasound with a sonosensitizer. Anticancer Res 31: 2425-2429, 2011.

2. Rosenthal I, Sostaric JZ and Riesz P: Sonodynamic therapy-a review of the synergistic effects of drugs and ultrasound. Ultrason Sonochem 11: 349-363, 2004.

3. Tsuru H, Shibaguchi H, Kuroki M and Yamashita Y: Tumor growth inhibition by sonodynamic therapy using a novel sonosensitizer. Free Radic Biol Med 53: 464-472, 2012.

4. Yumita N, Okuyama N, Sasaki K and Umemura S: Sonodynamic therapy on chemically induced mammary tumor: pharmacokinetics, tissue distribution and sonodynamically induced antitumor effect of gallium-porphyrin complex ATX-70. Cancer Chemother Pharmacol 60: 891-897, 2007.

5. Komori C, Okada K, Kawamura K, Chida S and Suzuki T: The sonodynamic antitumor effect of methylene blue on sarcoma180 cells in vitro. Anticancer Res 29: 2411-2415, 2009. 
6. Liu Q, Li X, Xiao L, Wang P, Wang X and Tang W: Sonodynamically induced antitumor effect of hematoporphyrin on Hepatoma 22. Ultrason Sonochem 15: 943-948, 2008.

7. Ohmura T, Fukushima T, Shibaguchi H, et al: Sonodynamic therapy with 5-aminolevulinic acid and focused ultrasound for deep-seated intracranial glioma in rat. Anticancer Res 31: 2527-2533, 2011.

8. Peng Q, Berg K, Moan J, Kongshaug M and Nesland JM: 5-Aminolevulinic acid-based photodynamic therapy: principles and experimental research. Photochem Photobiol 65: 235-251, 1997.

9. Zenzen V and Zankl H: Protoporphyrin IX-accumulation in human tumor cells following topical ALA- and h-ALA-application in vivo. Cancer Lett 202: 35-42, 2003.

10. Wu SM, Ren QG, Zhou MO, Peng Q and Chen JY: Protoporphyrin IX production and its photodynamic effects on glioma cells, neuroblastoma cells and normal cerebellar granule cells in vitro with 5-aminolevulinic acid and its hexylester. Cancer Lett 200: 123-131, 2003

11. Schick E, Kaufmann R, Ruck A, Hainzl A and Boehncke WH: Influence of activation and differentiation of cells on the effectiveness of photodynamic therapy. Acta Derm Venereol 75 276-279, 1995.

12. Wyld L, Burn JL, Reed MW and Brown NJ: Factors affecting aminolaevulinic acid-induced generation of protoporphyrin IX. Br J Cancer 76: 705-712, 1997.

13. Wyld L, Smith O, Lawry J, Reed MW and Brown NJ: Cell cycle phase influences tumour cell sensitivity to aminolaevulinic acid-induced photodynamic therapy in vitro. Br J Cancer 78: 50-55, 1998.

14. Sano M, Furuta T, Takahira K, et al: Cell-cycle-dependent efficacy of photodynamic therapy with ATX-S10(Na). Lasers Med Sci 20: 1-5, 2005.

15. Heinemann L, Simpson GR, Annels NE, et al: The effect of cell cycle synchronization on tumor sensitivity to reovirus oncolysis Mol Ther 18: 2085-2093, 2010

16. Huang X, Di Liberto M, Jayabalan D, et al: Prolonged early G(1) arrest by selective CDK4/CDK6 inhibition sensitizes myeloma cells to cytotoxic killing through cell cycle-coupled loss of IRF4. Blood 120: 1095-1106, 2012.

17. Hassan MAIA, Braam SR and Kruyt FAE: Paclitaxel and vincristine potentiate adenoviral oncolysis that is associated with cell cycle and apoptosis modulation, whereas they differentially affect the viral life cycle in non-small-cell lung cancer cells. Cancer Gene Ther 13: 1105-1114, 2006.

18. Connell CM, Wheatley SP and McNeish IA: Nuclear survivin abrogates multiple cell cycle checkpoints and enhances viral oncolysis. Cancer Res 68: 7923-7931, 2008.

19. Lv Y, Fang M, Zheng J, et al: Low-intensity ultrasound combined with 5-aminolevulinic acid administration in the treatment of human tongue squamous carcinoma. Cell Physiol Biochem 30: 321-333, 2012.

20. Song W, Cui H, Zhang R, Zheng J and Cao W: Apoptosis of SAS cells induced by sonodynamic therapy using 5 -aminolevulinic acid sonosensitizer. Anticancer Res 31: 39-45, 2011.
21. Khammanit R, Chantakru S, Kitiyanant Y and Saikhun J: Effect of serum starvation and chemical inhibitors on cell cycle synchronization of canine dermal fibroblasts. Theriogenology 70: 27-34, 2008.

22. Banfalvi G: Overview of cell synchronization. Methods Mol Biol 761: 1-23, 2011.

23. Gao Z, Zheng J, Yang B, et al: Sonodynamic therapy inhibits angiogenesis and tumor growth in a xenograft mouse model. Cancer Lett 335: 93-99, 2013

24. Vokes EE: The promise of biochemical modulation in combined modality therapy. Semin Oncol 21: 29-33, 1994.

25. Humphrey RM and Dewey WC: Radiosensitivity of normal and 5-bromodeoxyuridine treated mammalian cells during different phases of the cell cycle. Exp Cell Res 39: 483-495, 1965.

26. Ma LW, Moan J, Steen HB and Iani V: Anti-tumour activity of photodynamic therapy in combination with mitomycin $\mathrm{C}$ in nude mice with human colon adenocarcinoma. Br J Cancer 71: 950-956, 1995.

27. Shibata Y, Matsumura A, Yoshida F, et al: Cell cycle dependency of porphyrin uptake in a glioma cell line. Cancer Lett 129: 77-85, 1998.

28. Terasima $\mathrm{T}$ and Tolmach LJ: Variations in several responses of HeLa cells to x-irradiation during the division cycle. Biophys $\mathrm{J} 3$ : 11-33, 1963

29. Meikrantz W and Schlegel R: Apoptosis and the cell cycle. J Cell Biochem 58, 160-174 1995.

30. Yam CH, Fung TK and Poon RYC: Cyclin A in cell cycle control and cancer. Cell Mol Life Sci 59: 1317-1326, 2002.

31. Pagano M, Pepperkok R, Verde F, Ansorge W and Draetta G: Cyclin $\mathrm{A}$ is required at two points in the human cell cycle. EMBO J 11: 961-971, 1992.

32. Wang SJ, Hasham MG, Isordia-Salas I, Tsygankov AY, Colman RW and Guo YL: Regulation of cardiovascular signaling by kinins and products of similar converting enzyme systems - Upregulation of $\mathrm{Cdc} 2$ and cyclin A during apoptosis of endothelial cells induced by cleaved high-molecular-weight kininogen. Am J Physiol Heart Circ Physiol 284: H1917-H1923, 2003.

33. Meikrantz W and Schlegel R: Suppression of apoptosis by dominant negative mutants of cyclin-dependent protein kinases. J Biol Chem 271: 10205-10209, 1996.

34. Meikrantz W, Gisselbrecht S, Tam SW and Schlegel R: Activation of Cyclin a-Dependent Protein-Kinases during Apoptosis. Proc Natl Acad Sci USA 91: 3754-3758, 1994.

35. Wang XH, Song YJ, Ren JS and Qu XG: Knocking-Down Cyclin A(2) by siRNA Suppresses Apoptosis and Switches Differentiation Pathways in K562 Cells upon Administration with Doxorubicin. PLoS One 4: e6665, 2009.

36. Ekberg J and Persson J: Post-translational modification of cyclin A1 is associated with staurosporine and TNF alpha induced apoptosis in leukemic cells. Mol Cell Biochem 320: 115-124, 2009.

37. Hiromura K, Pippin JW, Blonski MJ, Roberts JM and Shankland SJ: The subcellular localization of cyclin dependent kinase 2 determines the fate of mesangial cells: role in apoptosis and proliferation. Oncogene 21: 1750-1758, 2002. 